\title{
Chorda tympani proper nerve responses to intra-arterial and surface stimulation of the tongue in rhesus monkey and rat
}

\author{
Hellekant, $\mathrm{G}$; et al
}

\begin{abstract}
The effect of intra-arterial injection of the proteins monellin, thaumatin and miraculin on the activity of the chorda tympani proper nerve were recorded in the rhesus monkey (Macaca mulatto) and the rat (Sprague-Dawley). The substances were injected into the blood stream to the lingual artery. It was found that monellin and thaumatin elicited a response only in the monkey and not in the rat. Acetylated thaumatin, a tasteless substance, gave no increase of the nerve activity. Miraculin had no effect in either species. $\mathrm{NaCl}$, sucrose and citric acid injected intra-arterially gave a response in both species. It is concluded that the responses to intra-arterial injections were caused by stimulation of the taste buds and not nerve fibers. The results suggest there are taste receptors also on the parts of the taste cells not facing the oral cavity. The finding that there was no cross-adaptation between intra-arterial and oral application supports this conclusion
\end{abstract}

DOI: https://doi.org/10.1093/chemse/11.4.557

Posted at the Zurich Open Repository and Archive, University of Zurich

ZORA URL: https://doi.org/10.5167/uzh-154440

Journal Article

Published Version

Originally published at:

Hellekant, G; et al (1986). Chorda tympani proper nerve responses to intra-arterial and surface stimulation of the tongue in rhesus monkey and rat. Chemical Senses, 11(4):557-566.

DOI: https://doi.org/10.1093/chemse/11.4.557 


\title{
Chorda tympani proper nerve responses to intra-arterial and surface stimulation of the tongue in rhesus monkey and rat
}

\author{
G.Hellekant, H.van der Wel, J.N.Brouwer, D.Glaser ${ }^{1}$, C.Hård af Segerstad \\ and T.W.Roberts
}

\begin{abstract}
Department of Veterinary Science and Wisconsin Regional Primate Center, 1655 Linden Drive, University of Wisconsin, Madison, WI 53706, USA, and ${ }^{1}$ Institute of Anthropology, University of Zürich, Switzerland
\end{abstract}

\begin{abstract}
The effect of intra-arterial injection of the proteins monellin, thaumatin and miraculin on the activity of the chorda tympani proper nerve were recorded in the rhesus monkey (Macaca mulatta) and the rat (Sprague-Dawley). The substances were injected into the blood stream to the lingual artery. It was found that monellin and thaumatın elıcited a response only in the monkey and not in the rat. Acetylated thaumatin, a tasteless substance, gave no increase of the nerve activity. Miraculin had no effect in either species. $\mathrm{NaCl}$, sucrose and citric acid injected intra-arterially gave a response in both species. It is concluded that the responses to intra-arterial injections were caused by stimulation of the taste buds and not nerve fibers. The results suggest there are taste receptors also on the parts of the taste cells not facing the oral cavity. The finding that there was no cross-adaptation between intra-arterial and oral application supports this conclusion.
\end{abstract}

\section{Introduction}

The mammalian taste buds are composed of elongated cells exposed to the contents of the oral cavity by means of cellular extensions, microvilli. Application of compounds dissolved in the fluid outside the microvilli, i.e. oral stimulation, is the normal way to elicit a taste sensation. It is known from clinical studies that compounds injected intravascularly, intralingual stimulation, can elicit a taste sensation (Winternitz et al., 1931). During intralingual stimulation the molecular size of the infused compounds plays a decisive role in their ability to pass from the capillaries to the extracapillary space. Compounds with a radius of more than $50 \dot{\mathrm{A}}$ have a very limited capacity to diffuse through the capillary membrane, while compounds with a radius of $16 \AA$ or less readily diffuse through the membrane (Lanken et al., 1985).

We have for several years studied the oral effects of three proteins: monellin, thaumatin and miraculin. Monellin, mol. wt 11000 (van der Wel, 1972; Morris and Cagan, 1972) and thaumatin, mol. wt 22000 (van der Wel and Loeve, 1972) have an intensely sweet taste in man and all other catarrhine primates (Glaser et al., 1978; Hellekant $e t$ al., 1980b) but not in the rat and some other non-catarrhine mammals (Hellekant 1975, 1976a; Hellekant et al., 1976). Miraculin, a glycoprotein with a mol. wt of 44000 (Brouwer et al., 1986; Kurihara and Beidler, 1968), does not taste sweet in itself but adds sweetness (Bartoshuk et al. , 1969) and increases the neural response to sour solutions in man (Diamant et al., 1972) and other simian primates (Hellekant, 1977; Brouwer et al., 1983) but not in prosimian primates and other mammals (Hellekant, 1976b; Hellekant et al. , 1981). From their molecular weight monellin, thaumatin and miraculin can be estimated to have a molecular radius less than $25 \dot{A}$ which may allow them to pass the capillary membrane and perhaps reach the taste buds from within. Moreover tight junctions in the apical parts of the cells of the taste bud make it unlikely that a 
stimulus can pass from the vascular side of the microvilli in the taste pore (Murray and Murray, 1970).

Since the present thinking is that taste is the result of an interaction between a compound and a specialized set or sets of receptors on the microvilli (e.g. Crosby and DuBois, 1981; van der Heijden et al. , 1985a,b) it would be of interest to see if intralingual stimulation with these compounds would elicit a taste nerve response. If this is the case it will show that these compounds are able to penetrate the capillary walls, and may suggest that their receptors are distributed not only on parts that are in contact with the oral cavity.

As mentioned, the gustatory effects of monellin, thaumatin and miraculin are limited to special primate groups. Thaumatin and monellin gave no nerve response in the rat chorda tympani (Hellekant, 1975; Dugas du Villard et al., 1980) nor does miraculin exert the same effects in the rats as it does in primates (Diamant $e t$ al., 1972). Consequently the rat can be used as a control that the effects of intralingual stimulation with these compounds in the monkey are not caused by unspecific stimulation of nerve endings.

\section{Methods}

The following solutions were used for oral stimulation: $0.0035 \mathrm{M}$ acesulfam-K, $0.04 \mathrm{M}$ ascorbic acid, $0.0018 \mathrm{M}$ aspartame, $0.02 \mathrm{M}$ citric acid, $0.015 \mathrm{M}$ D-tryptophan, $0.1 \mathrm{M}$ $\mathrm{NaCl}, 0.01 \mathrm{M}$ quinine hydrochloride, $0.3 \mathrm{M}$ sucrose, $0.75 \mathrm{M}$ xylitol, $0.02 \% \mathrm{w} / \mathrm{v}$ monellin and $0.02 \% \mathrm{w} / \mathrm{v}$ thaumatin. All these solutions were made up in tap water which also was used to rinse the tongue between stimulations. The compounds used for intralingual stimulation were dissolved in saline $(0.9 \% \mathrm{w} / \mathrm{v} \mathrm{NaCl})$. They consisted of $0.01 \mathrm{M}$ citric acid, 0.3 or $0.4 \mathrm{M} \mathrm{NaCl}, 0.3 \mathrm{M}$ sucrose, $0.04 \% \mathrm{w} / \mathrm{v}$ monellin, $0.04 \%$ $\mathrm{w} / \mathrm{v}$ thaumatin, and $0.04 \% \mathrm{w} / \mathrm{v}$ acetylated thaumatin (not sweet). Approximately $1 \mathrm{ml}$ solution was injected in the monkey and $0.3 \mathrm{ml}$ in the rat. Miraculin was injected either as a short lasting bolus to test its possible direct taste effects or as a slow infusion to study its possible taste modifying effects. Then up to $10 \mathrm{ml}$ was injected in the monkey and $1 \mathrm{ml}$ in the rat of a concentration of $3 \mathrm{mg} / \mathrm{ml}$ over $3 \mathrm{~min}$. As a control, $2 \%$ methylene blue was injected into the lingual artery to show that compounds injected in this manner could reach the fungiform papillae. It gave a shortlasting color change of the ipsilateral tongue surface.

Four rhesus monkeys (Macaca mulatta), two of each sex, and five male Sprague-Dawley rats were used. The monkeys were immobilized and intubated after an i.m. injection of ketamin, $20 \mathrm{mg} / \mathrm{kg}$ body wt. The anesthesia was maintained by administrations of pentobarbital through a cannula in a radial vein. An incision was made through the skin along the mandible just medial to the mandibular angle. Following transection of the superficial muscle layers, blunt dissection was used to expose the caudo-medial side of the medial pterygoid muscle. Dissection into the caudal edge of the muscle a few $\mathrm{mm}$ before its origin at the pterygoid plate of the skull exposed the chorda tympani proper nerve usually covered with a venous sinus. The nerve was dissected free between its divergence from the lingual nerve and the tympanic bulla. The rats were anesthetized with a combination of Hypnorm ${ }^{\oplus}$ and pentobarbital i.m., and the same surgical approach was used. 
insas 1

$1 \mathrm{~min}$

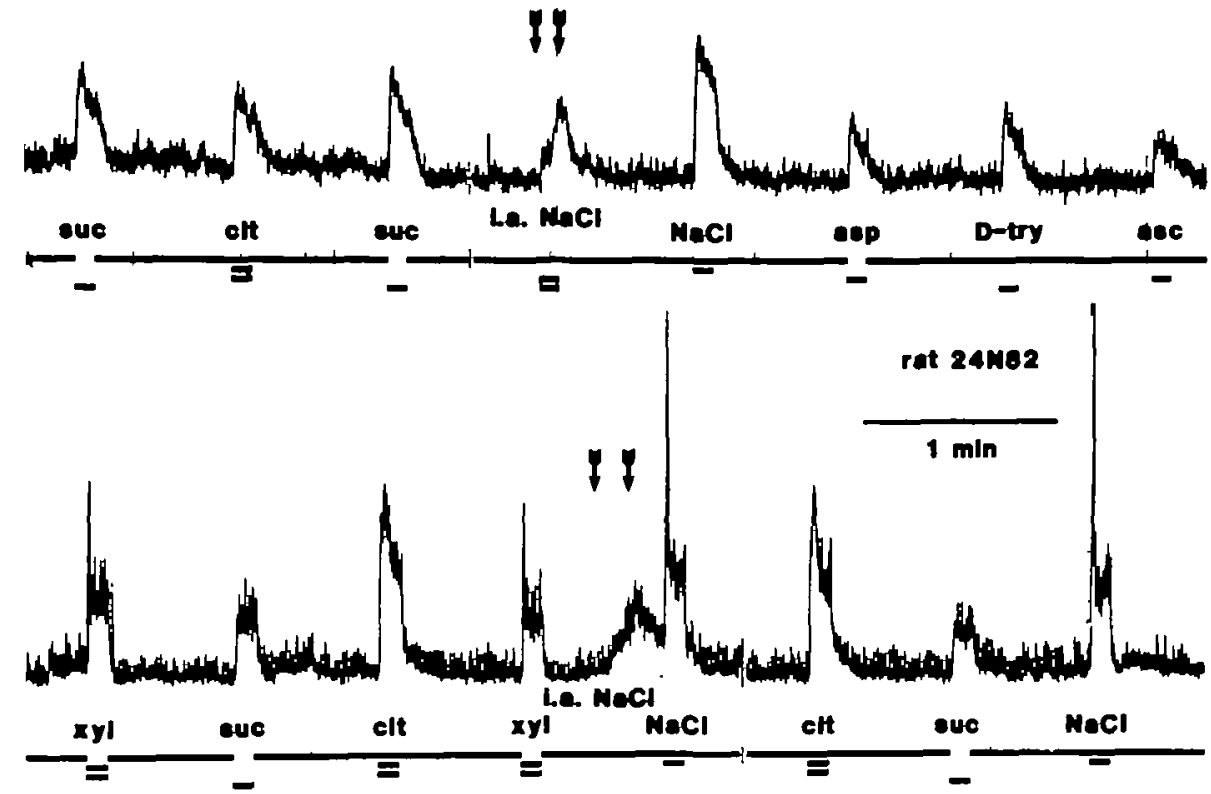

Fig. 1. All responses, except the ones marked with arrows, were the results of oral taste stimulation The top record was derived from a monkey while the bottom one is from a rat. The trace between the arrows shows the effect on the nerve activity of $7-10 \mathrm{~s}$ intralingual stimulation with $0.4 \mathrm{M} \mathrm{NaCl}$. Abbreviations: suc, sucrose; cit, citric acid; asp, aspartame; D-try, D-tryptophane; asc, ascortic acid; xyl, xylitol; 1 a.. intra-arterial.

For the intra-arterial injection of taste stimuli the external carotid artery was dissected in both species. In the monkey the lingual artery leaves the carotid artery either as a single branch or together with the facial artery and in some cases with the superior thyroid artery (McCoy, 1964). Both of the latter arteries were ligated while the blood flow through the lingual artery was left unrestricted. In the rat the lingual artery is given off as a separate branch. In both species the catheter used for infusion was inserted peripherally to the lingual branch in the continuation of the external carotid artery. The catheter was made of polythene tubing. The cannulation procedure did not restrict the blood flow to the tongue and allowed injection directly into the blood stream to the lingual artery. As a control of the general condition of the animal the systemic blood pressure was recorded in the right femoral artery.

The overall activity of the chorda tympani nerve was recorded with a PAR 113 amplifier, monitored over a loudspeaker and an oscilloscope, and fed into a recorder (Gould ES 1000) together with the output from an integrator and a signal, which in binary form indicated the type of stimulus used and stimulation time.

The surface of the tongue was stimulated with a Taste-O-Matic system (Hellekant et al., 1980a). The intralingual stimuli were administered by a peristaltic pump (Holter RD 074) in the rat and an infusion pump (Harvard Apparatus model 2274) in the monkey. 

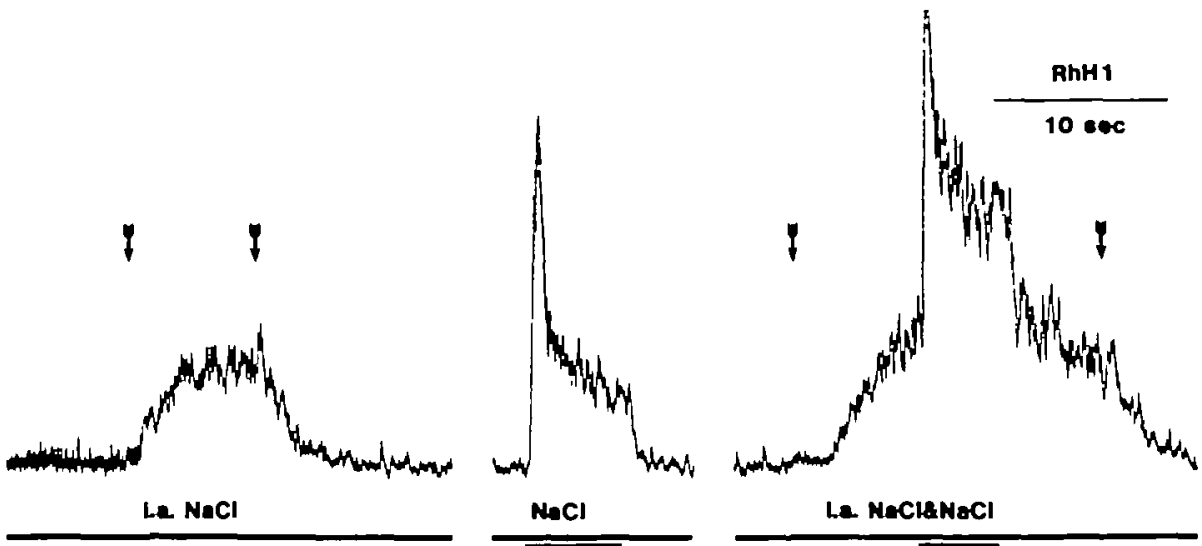

Fig. 2. From the left the traces show the response to intralingual $0.4 \mathrm{M} \mathrm{NaCl}$, oral $0.1 \mathrm{M} \mathrm{NaCl}$, and oral $0.1 \mathrm{M} \mathrm{NaCl}$ during intralingual $0.4 \mathrm{M} \mathrm{NaCl}$ stimulation. The intralıngual stımulations are indicated by the arrows while the signal below shows the oral stimulation.

\section{Results}

The response of $\mathrm{NaCl}$, sucrose and citric acid

From the results shown in Figure 1 it is evident that oral and intralingual stimulation with $\mathrm{NaCl}$ elicited a chorda tympani response in both species. A series of other stimuli was also applied to the surface of the tongue which was constantly rinsed with water between oral and during intralingual stimulation.

It ought to be observed that the response to oral stimulation with $\mathrm{NaCl}$ following shortly after the intralingual stimulation with $\mathrm{NaCl}$ in the rat record has the same magnitude as the response to $\mathrm{NaCl} 1.5 \mathrm{~min}$ later; there was no cross-adaptation between the intralingual and oral stimulation in either species. This is further shown in Figure 2 which displays three consecutive recordings during, from the left, intralingual $\mathrm{NaCl}$ stimulation, oral $\mathrm{NaCl}$ and oral $\mathrm{NaCl}$ during intralingual $\mathrm{NaCl}$ stimulation in a monkey. Parts of the recording between stimulations have been excluded to condense Figure 2. Although the peak of the oral response during the intralingual stimulation was hidden in the nerve trace above it (not shown in Figure 2), it is evident that its magnitude was the same as the response to the oral stimulation alone.

With regard to the responses to intralingual stimulation with $0.01 \mathrm{M}$ citric acid and $0.3 \mathrm{M}$ sucrose, they always elicited a nerve response in both species. A comparison between the response characteristics to $\mathrm{NaCl}$, citric acid and sucrose, showed a smaller amplitude and later onset to sucrose in both species. Further, in both species, intralingual administration of citric acid had a deleterious effect, because the responses to both surface and intralingual stimulation decreased with repeated intralingual stimulation with citric acid. In both species intra-arterially injected saline did not elicit any response.

\section{The response to thaumatin and monellin}

Figure 3 presents results of intralingual stimulation with $0.04 \%$ thaumatin, and $0.04 \%$ 

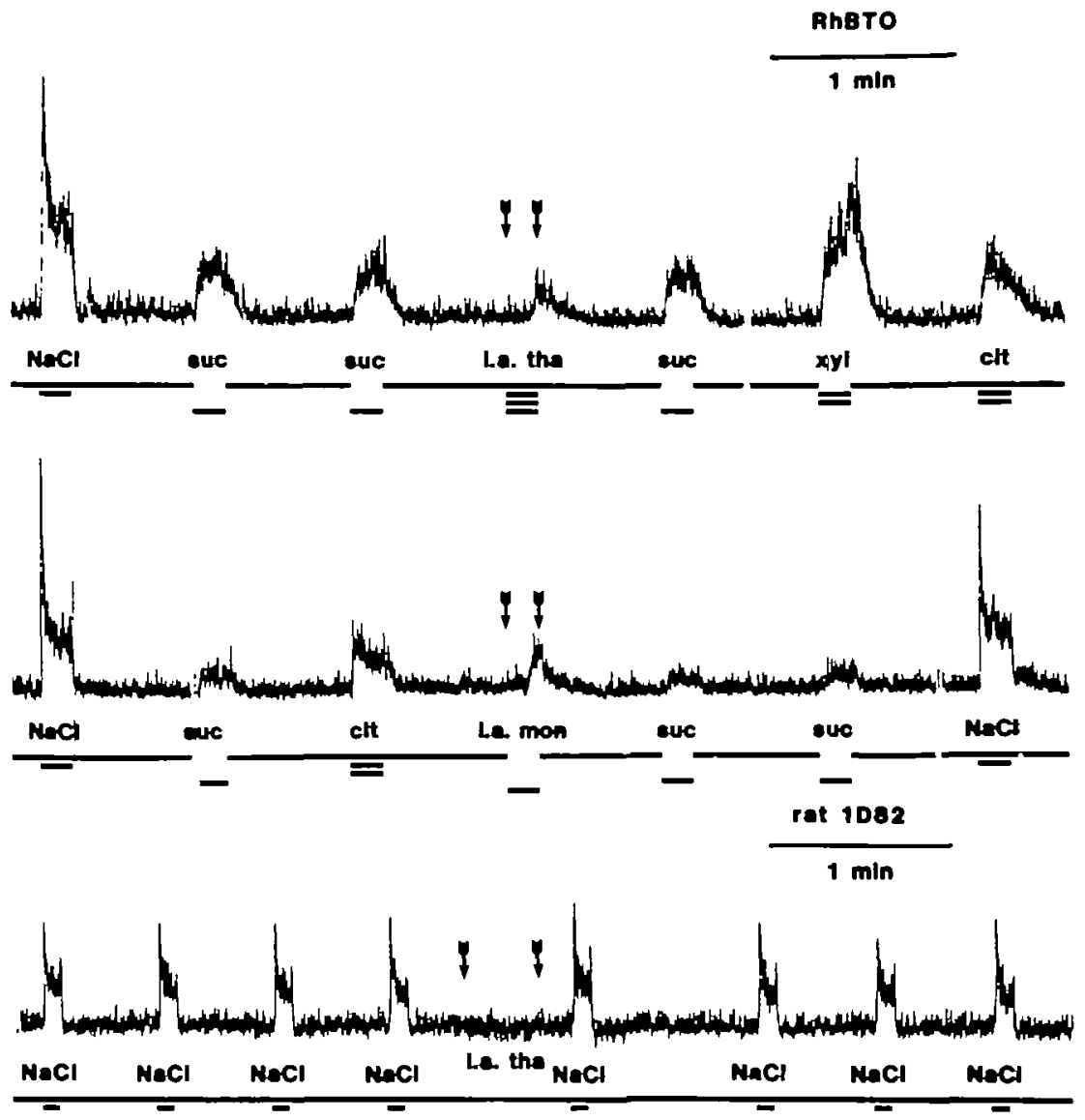

Fig. 3. Intralingual stimulation, indicated by the arrows, with $0.04 \% \mathrm{w} / \mathrm{v}$ thaumatin and $0.04 \% \mathrm{w} / \mathrm{v}$ monellin in a monkey (top) and a rat (bottom). Abbreviations as in Figure 1, tha, thaumatin; mon, monellin.

monellin in a monkey and $0.04 \%$ thaumatin in a rat. There was a significant response to thaumatin in the monkey recording, but none in the rat, although the infusion lasted considerably longer in the rat than in the monkey. Intralingual stimulation with monellin elicited a similar response as oral in the monkey (the middle trace in Figure 3 ) but none in the rat. In the monkey, the intralingual response had a similar amplitude and rise time as response to oral stimulation with thaumatin.

In the recordings from the monkey in Figure 3 it should be noticed that the responses to oral stimulation with $0.3 \mathrm{M}$ sucrose before and after the intralingual thaumatin or monellin stimulation have about the same heights. This is in contrast to the effects of oral thaumatin or monellin stimulation, which depress the response to sucrose for several minutes (Brouwer et al., 1973). In Figure 4 responses from a monkey to orally applied sucrose were plotted after intralingual and oral thaumatin stimulation. In contrast to the results after the oral application, there was no depression of the sucrose responses after the intralingual application. This demonstrates that there was no cross-adaptation between oral and intralingual stimulation. 
\% suc/salt response

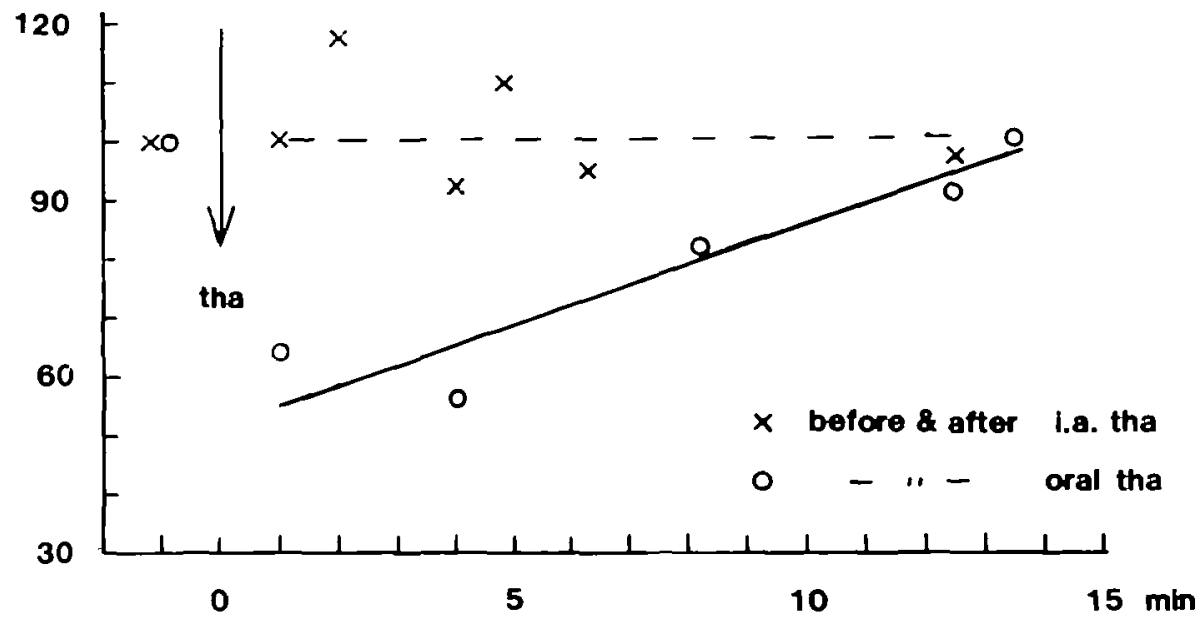

Fig. 4. The diagram shows the response to oral stımulation with sucrose after intralıngual thaumatın $(x)$ and oral thaumatin $(\mathrm{O})$. The sucrose responses were expressed as a percentage of nearest $\mathrm{NaCl}$ response. The response immediately before the thaumatin was then assigned the value $100 \%$ and the following responses calculated in percent of this value.

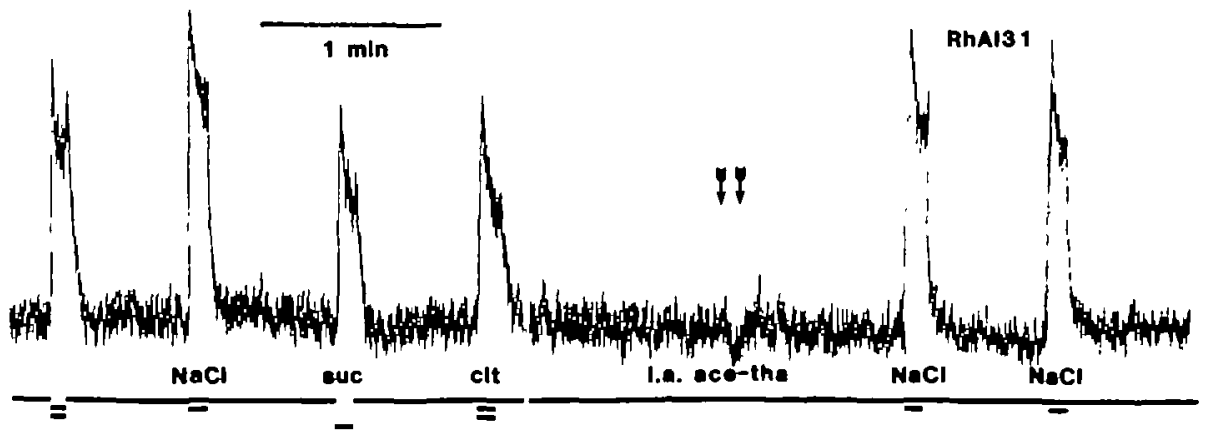

Fig. 5. Intralingual stimulation with non-sweet $0.04 \%$ acetylated thaumatin in the monkey. Abbreviations as in previous Figures.

The response to acerylated thaumatin

Figure 5 shows that intralingual stimulation with $0.04 \%$ acetylated thaumatin, which is not sweet to man and does not elicit a nerve or behavioral response in rhesus monkey, did not elicit an increase of the nerve activity in the monkey. On the contrary, there was a small dip in nerve activity, the cause of which we cannot explain. No increase was recorded in the rat.

\section{The effect of miraculin}

Figure 6 consists of recordings before (top record) and after (bottom record) intralingual administration with a total of $10 \mathrm{mg}$ of miraculin infused over a 3-min period which 


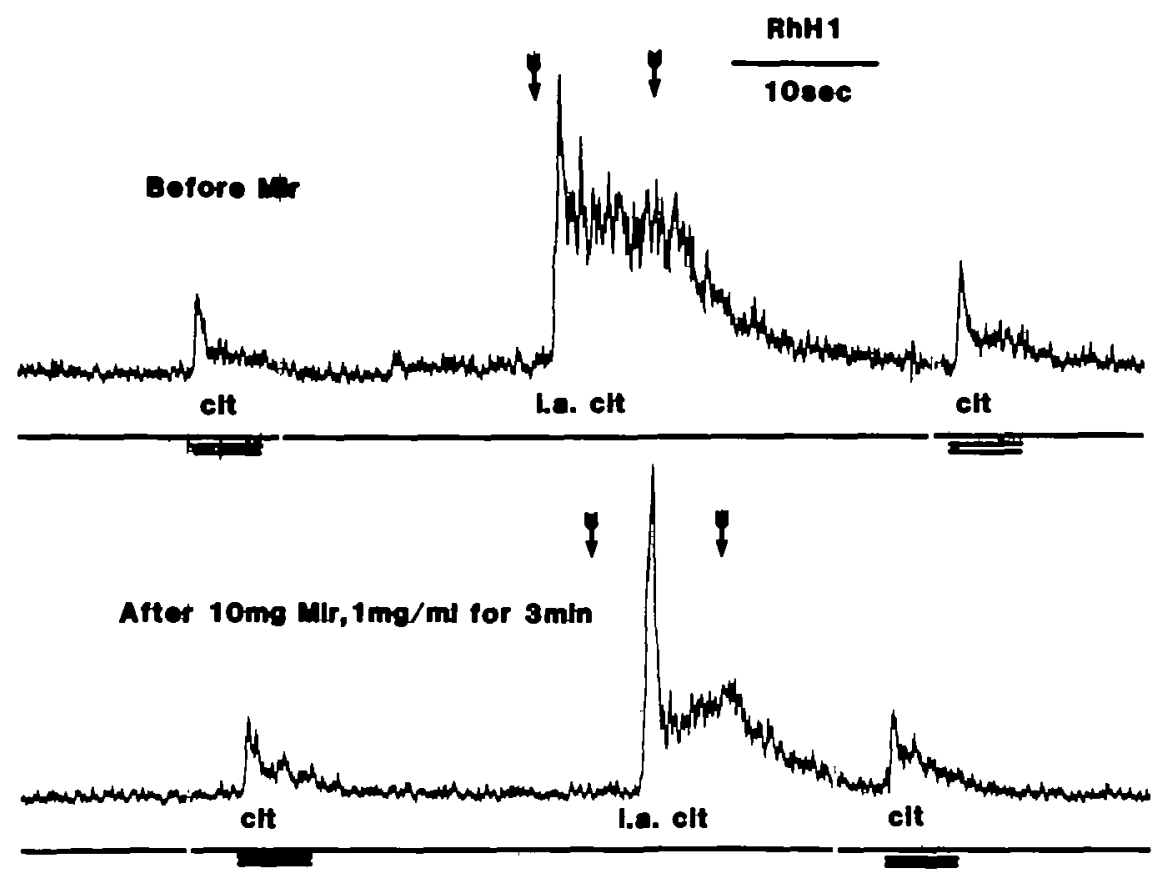

Fig. 6. Recordıngs before and after intralıngual administration with a total of $10 \mathrm{mg}$ of miraculin in a monkey. The miraculin was infused over a 3 -min period which is not included in the figure.

is not included. During this infusion the nerve activity was unchanged. In Figure 6, citric acid was orally applied twice and intralingually once in each record. A comparison of the response magnitudes before and after the miraculin shows that there was no increase of the responses to either intralingual or orally applied citric acid after miraculin. On the contrary, a decrease in the tonic part of the intravascular response was recorded which may be attributed to the deleterious effect of citric acid already mentioned.

The results were similar in the rat. Miraculin has no effect on the responses to intralingual stimulation with citric acid.

\section{Discussion}

The stimulus was injected into the blood stream as it passed by the orifice of the catheter and then carried to the taste buds in an arterial tree that differs not only between the species but also between animals of the same species (McCoy, 1964). Consequently, knowledge of stimulus volume, concentration and exact time for arrival of stimulus at site of stimulation, which could allow a more quantitative analysis, were not available. Conclusions can still be drawn from the intravascular results although they are more of a qualitative than a quantitative nature. This was pointed out already by Bradley (1970).

Our data (Figure 3) show that in the rhesus monkey both thaumatin and monellin, when injected intra-arterially into the tongue, elicit response patterns in the chorda tympani comparable to those obtained on oral stimulation (Brouwer et al., 1973). Acetylated 
thaumatin, which does not elicit a taste response in man (van der Wel and Bel, 1976) or in monkey (own observations, in preparation) elicited intralingual effects in parallel with the oral ones.

The capillaries entering the fungiform papillae converge towards the surface and form rich anastomoses around the taste bud (Hellkant, 1976c). To elicit a response in the chorda tympani nerve, the intra-arterial compounds have to pass from the capillaries to the extravascular space. From other capillary beds it is known that the molecular size of a compound plays a decisive role for its ability to penetrate the capillary wall. Lanken et al. (1985) studied the influence of molecular size on the passage of $\left[{ }^{3} \mathrm{H}\right]-$ dextrans through the capillary wall of lungs. They found that the distribution of dextrans was even between the extravascular and intravascular space $(L / P)$ up to a radius of $16 \dot{A}$, but then decreased with increasing radius of the molecule, and approached zero at $50 \AA$. Based on data from ultracentrifugal molecular weight determination we estimate monellin, thaumatin, and acetylated thaumatin to be less than $15 \AA$ in radius. Assuming that the capillaries of the tongue have the same characteristics, then it would be possible for monellin, thaumatin and acetylated thaumatin to pass the capillary wall.

The interpretation of the absence of an effect of intralingually applied miraculin is problematic. From the estimated effective molecular radius of approximately $23 \AA$ (derived from the diffusion coefficient $D_{25, w}=9.4 \times 10^{-7} \mathrm{~cm}^{2} / \mathrm{s}$ ) one would expect it to be able to pass the capillary wall: Lanken $e t$ al. (1985) report $L / P$ ratios of $0.7-0.9$ for molecules with a radius of approximately $23 \AA$. Moreover they showed that serum albumin (mol. wt. 67000 ; effective molecular radius $36 \AA$ ) has an $L / P$ ratio of 0.76 and they refer to another study which showed that protein fractions with radii of up to $80 \AA$ passed through capillaries ( $L / P$ ratio approximately 0.5 ). Thus the size of miraculin should not prevent its passage. Bradley (1973) showed in the rat that repeated stimulation in general rendered the preparation unable to respond to intralingual stimulation. In the way we carried out the experiments only a detrimental effect of intralingual stimulation with citric acid was noticed. Since it has been shown that the responses to oral citric acid stimulation are enhanced about 50\% after miraculin (Hellekant, 1977; Brouwer et al., 1983), the detrimental effects could not have completely obscured an enhancement by miraculin if there was one. Furthermore, we tried to avoid these effects by making the periods between stimulations as long as possible and limit the number of stimulations. The conclusion is that miraculin does not act when applied intravascularly.

Since continuous rinsing of the tongue removes orally applied stimuli not only from the tongue but also from the taste pores, it is very unlikely that the effective stimuli at intravascular application could have reached their sites for stimulation via the taste pore. Some other sites for stimulation must be considered. The possibility must be considered that they may have stimulated taste nerve fibers directly (Farbman and Hellekant, 1978). However, Beidler (1970) already stated that these nerve endings were not chemoreceptive and also Bradley (1973) argued against this. There are some more arguments against the nerve endings as sites for stimulation. In our experiments, the rat showed no nerve response at either intralingual or oral stimulation with monellin and thaumatin in contrast to the monkey. If the response in the monkey was caused by direct stimulation of nerve fibers, the capillary permeability to thaumatin and monellin has to be different in the rat from the rhesus monkey or the taste nerve fibers of the 
two species have to react differently to direct exposure to thaumatin and monellin. Earlier studies show that oral taste stimulation elicits the same taste quality in man (e.g. Brobeck, 1979) and in the rat, (Bradley and Mistretta, 1971) as intra-vascular. If the response was caused by direct stimulation of nerve fibers and the theory of labelled lines is valid, the stimuli must have affected selective fibers. This means that these fibers have specific receptors on its membrane or that the taste cells have intramural receptors within the taste bud, in contact with the extracellular fluid. The final solution to this question has to await results of experiments that allow direct identification of stimulus in the tissue after intralingual application.

Assuming that the taste results from a stimulus/receptor interaction, then the findings describe here indicate that stimulus sites for monellin and thaumatin are present not only on the microvilli but in other areas of the taste bud too. This should make it easier to visualize the binding sites for thaumatin and monellin.

There was no cross-adaptation between the oral and intravascular stimuli. Since crossadaptation (Hellekant, 1969) is considered to be the result of a competition for taste receptors, it indicates that the oral and intralingual stimuli engage different receptor areas as suggested earlier by Bradley (1973). This indicates further that cross-adaptation is not the result of a limitation of generator potential or similar events occurring after the binding of stimulus to receptors, but is due to a limitation of available receptors on the membrane of the sensory cells. This adds value to the use of cross-adaptation as a tool to learn more about similar receptors on other parts of the taste cells.

In conclusion, the response to intralingual stimulation in the monkey was caused by stimulation of monellin and thaumatin of its taste buds and not its taste nerves. Since there is no support for the idea that these compounds reach the taste cells via the taste pore after intralingual application, the results indicate that there are receptors to these compounds on other parts of the cells within the taste bud.

\section{Acknowledgements}

This study was supported by a grant from NIH, NS17021, and Hatch 2962.

\section{References}

Bartoshuk,L.M., Dateo,G.P., Vandenbelt,D.J., Buttrick,R.L. and Long,L.,Jr (1969) Effects of Gymnema sylvestre and Synsepalum dulcificum on taste in man. In Pfaffmann,C. (ed.), Olfaction and Taste III. Rockefeller University Press, NY, pp. 436-444.

Beidler,L.M. (1970) Taste bud cells act as receptors and not merely as chemical filters. In Second Symposium on Oral Sensation and Perception. Thomas, Springfield, IL, pp. 106-108.

Bradley,R.M. (1970) Investigations of intravascular taste using the perfused rat's tongue. Ph.D. thesis, Florida State University.

Bradley,R.M. (1973) Electrophysiological investigations of intravascular taste using perfused rat tongue Am. J. Physiol, 224, 300-304.

Bradley,R.M. and Mistretta,C.M. (1971) Intravascular taste in rats as demonstrated by conditioned aversion to sodium sacchann. J. Comp. Physiol. Psychol., 75, 186-189.

Brobeck,J.R. (ed.) (1979) Best and Taylor's Physiological Basis of Medical Practice, 10th edn. Williams and Wilkins, Baltimore, pp. 3-159.

Brouwer,J.N., van der Wel,H., Francke,A. and Henning,G.J. (1968) Miraculin, the sweetness-inducing protein from miracle fruit. Narure, 220, 373-374.

Brouwer,J.N., Hellekant,G., Kasahara,Y., van der Wel,H. and Zotterman, Y. (1973) Electrophysiological study of the gustatory effects of the sweet proteins monellin and thaumatin in monkey, guinea pig and rat. Acta Physiol. Scand., 89, 550-557.

Brouwer,J.N., Glaser,D., Hârd af Segerstad,C., Hellekant,G., Ninomiya,Y. and van der Wel,H. (1983) The sweetness-inducing effect of miraculin; behavioural and neurophysiological experiments in the thesus 
monkey (Macaca mulatta). J. Physiol, 337, $221-240$.

Crosby,G.A. and DuBois,G.E. (1981), Sweeteners and receptor sites. In Lamble,J.W. (ed.), Towards Understanding Receptors. Elsevier/North-Holland, Amsterdam, pp. 223-229.

Diamant,H., Hellekant,G. and Zotterman,Y. (1972) The effect of miraculin on the taste buds of man, monkey and rat. In Schneider,D. (ed.), Olfaction and Taste IV. Wissenschaftliche Verlagsgesellschaft mbH, Stuttgart, pp. $241-243$.

Dugas du Villard,X., van der Wel,H. and Brouwer,J.N. (1980) Enhancement of the perceived sucrose sweetness in the rat by thaumatin. Chem. Senses, 5, 93-98.

Farbman,A.I. and Hellekant,G. (1978) Quantitatıve analyses of the fiber population in rat chorda tympani nerves and fungiform papillae. Am. J. Anat., 153, 509-521.

Glaser,D., Hellekant,G., Brouwer,J.N. and van der Wel,H. (1978) The taste responses in primates to the proteins thaumatin and monellin and their phylogenetic implications. Folia Primatol., 29, 56-63.

Hellekant,G. (1969) Inhibitory processes in gustation. Acta Physiol. Scand., 75, 39-48.

Hellekant,G. (1975) Different types of sweet receptors in mammals. In Denton,D.A. and Coghlan,J.P. (eds), Olfaction and Taste V. Academic Press, New York, pp. 15-21.

Hellekant,G. (1976a) On the gustatory effects of monellin and thaumatin in dog, hamster, pig and rabbit. Chem. Sens. Flavor, 2, 97-105.

Hellekant,G. (1976b) On the gustatory effects of gymnemic acid and miraculin in dog, pig and rabbit. Chem. Sens. Flawr, 2, 85-95.

Hellekant,G. (1976c) The blood circulation of the tongue. In Kawamura,Y. (ed.), Frontiers of Oral Physiology. S.Karger, Basel, Vol. 2, pp. 130-145.

Hellekant,G. (1977) Effects of miraculin and gymnemic acid in the rhesus monkey (Macaca mulatta). In Katsuki,Y., Sato,M., Takagi,S.F. and Oomura,Y. (eds), Food Intake and Chemical Senses. University of Tokyo Press, Tokyo, pp. 201-210.

Hellekant,G., Glaser,D., Brouwer,J.N. and van der Wel,H. (1976) Gustatory effects of miraculin, monellin and thaumatin in the Saguinus midas tamarin monkey studied with electrophysiological and behavioural techniques. Acta Physiol. Scand, 97, 241-250.

Hellekant,G., Aronsson, T. and Karlbom,U. (1980k) Neural (electro-physiological) methods in chemoreception research. J. Anim. Physiol. Anim. Nutr., Suppl. 11, 21-26.

Hellekant,G., Glaser,D., Brouwer,J. and van der Wel,H. (1980b) Study of behavioural and neurophysiological experiments on the sweet taste in five primates. In van der Starre,H. (ed.), Olfaction and Taste VII. IRL. Press, Oxford, pp. 183-186.

Hellekant,G., Glaser,D., Brouwer,J. and van der Wel,H. (1981) Gustatory responses in three prosimian and two simian primate species (Tupaia glis, Nycticebus coucang, Galago senegalensis, Callithrix jacchus jacchus and Saguinus midas niger) to six sweeteners and miraculin and their phylogenetic implications. Chem. Senses, 6, 165-173.

Kurihara,K. and Beidler,L.M. (1968) Taste-modıfying protein from miracle fruit. Science, 161, $1241-1243$.

Lanken,P.N., Hansen-Flaschen,J.H., Sampson,P.M., Pietra,G.G., Haselton,F.R. and Fishman,A.P. (1985) Passage of uncharged dextrans from blood to lung lymph in awake sheep. J. Appl. Physiol., 59, 580-591.

McCoy,H.A. (1964) The regional anatomy of the temporal and infratemporal areas of the rhesus monkey (Macaca mulatta). M.S. thesis, Medical College of South Carolina.

Morris,J.A. and Cagan,R.H. (1972) Purification of monellin, the sweet principle of Dioscoreophyllum cumminsil. Biochim. Biophys. Acta, 261, 114-122.

Murray,R.G. and Murray,A. (1970) The anatomy and ultrastructure of taste endings. In Wolstenholme,G.E.W. and Knight,J. (eds), Taste and Smell in Vertebrates. J. and A.Churchill, London, pp. 3-30.

van der Heijden,A., van der Wel,H. and Peer,H.G. (1985a) Structure-activity relationships in sweeteners. 1. Nitroanilınes, sulphamates, oximes, isocoumarins and dipeptides. Chem. Senses, 10, 57-72.

van der Heijden,A., van der Wel,H. and Peer,H.G. (1985b) Structure-activity relationships in sweeteners. II. Saccharins, acesulfames, chlorosugars, tryptophans and ureas. Chem. Senses, 10, 73-88.

van der Wel,H. (1972) Isolation and characterization of the sweet principle from Dioscoreophyllum cumminsii (Stapf) Diels. FEBS Lett., 21, 88-90.

van der Wel,H. and Bel,W.J. (1976) Effect of acetylation and methylation on the sweetness intensity of thaumatin 1. Chem. Sens. Flavor, 2, 211-218.

van der Wel,H. and Loeve,K. (1972) Isolation and characterization of thaumatin I and II, the sweet-tasting proteins from Thaumatococcus daniellii Benth. Eur. J. Biochem., 31, 221-225.

Winterniz,M., Deutsch,J. and Brüll,Z. (1931) Eine klinisch brauchbare Bestimmungsmethode der Blutumlaufszeit mittels Decholininjektion. Med. Klin. Munic., 27, 986-988.

Received April 1986; accepted July 1986 